\title{
SEROPREVALENCE AND MOLECULAR DIAGNOSIS OF BRUCELLA ABORTUS AND BRUCELLA MELITENSIS IN BANGLADESH
}

\author{
M. A. S. Sarker ${ }^{1}$, R. R. Sarker ${ }^{1}$ M. M. Begum ${ }^{2}$, N. M. Shafy ${ }^{1}$, M. T. Islam ${ }^{1}$, M. A. Ehsan ${ }^{1}$, P. K. \\ Bhattacharjee $^{1}$, M. F. Rahman ${ }^{3}$, F. Melzer ${ }^{4}$, H. Neubauer ${ }^{4}$ and M. S. Rahman ${ }^{1 *}$
}

${ }^{1}$ Department of Medicine, Bangladesh Agricultural University, Mymensingh; ${ }^{2}$ Youth Training Center, Munshiganj, Bangladesh; ${ }^{3}$ Commandant Armed Forces Medical College, Dhaka Cantonment; ${ }^{4}$ Federal Research Institute for Animal Health, Jena, Germany

\begin{abstract}
The importance of brucellosis is primarily due to its public health significance and economic loss for the animal industry. The present study was performed to determine the seroprevalence of brucellosis in man and animals. A total of 1,452 samples (cattle 913, buffaloes 99, sheep 40, goats 50 and persons 350) were collected from Central Cattle Breeding and Dairy Farms, Savar, Dhaka and 5 districts (Mymensingh, Jamalpur, Gaibandha, Rangpur and Bagerhat) of Bangladesh. All samples were screened by RBT and the RBT positive sera were re-tested with SAT CFT, ELISA and qRT-PCR. Out of 913 cattle and 99 buffalo sera, 48 cattle and 7 buffalo sera showed positive reaction to RBT i.e. prevalence of brucellosis is $5.3 \%$ in cattle and $7.1 \%$ in buffaloes. The 350 human sera and all sheep and goats samples were negative to RBT. Among the RBT positive sera, 12 sera were found to contain Brucella DNA by genus specific IS711 quantitative real time PCR (qRT-PCR); and all PCR positive samples were found to contain Brucella abortus DNA. This report confirms that B. abortus is endemic in cattle and buffaloes in Bangladesh.
\end{abstract}

Key words: Brucellosis, molecular diagnosis, Bangladesh

\section{INTRODUCTION}

Brucellosis is an ancient and one of the world's most widespread zoonotic diseases affecting both public health and animal production. It is endemic in many developing countries of Asia, Africa and Latin America including Bangladesh. Brucellosis is an important disease of animals caused by small non-motile coccobacilli shaped Gram-negative bacteria. Brucellosis can affect domestic animals (like cattle, buffaloes, sheep, goats, pigs) and humans. The genus Brucella has 12 species on the basis of host specificity. Important zoonotic Brucella species are B. abortus, B. suis and B. melitensis. Brucellosis in cattle is caused almost exclusively by B. abortus which causes abortion and infertility in dairy cows and in small ruminants (sheep and goats), brucellosis in small ruminants is caused by $B$. melitensis. There are some areas where the co-existence of cattle and small ruminants facilitate cattle infection with B. melitensis (Samaha et al., 2008). Cattle can also become transiently infected by B. suis biovar 1 with the mammary gland as their preferred site (Olsen and Hennager, 2010). Domestic animals get infection from ingestion of contaminated feed and water, inhalation of aerosolized bacteria, sexual intercourse and direct contact with contaminated materials (Radostits et al., 2000). Almost every human case is directly or indirectly linked to animals or their products. So, the species of Brucella responsible for human infection will also reflect the prevalent species in animal populations. Tourists or business travelers to endemic areas may acquire brucellosis by consumption of unpasteurized milk or dairy products. They may also import contaminated cheese or other dairy products into their countries and infect their families (Godfroid et al., 2005; FAO, 2006). Human infections can result from direct contact with infected animals and brucellae can be transmitted to consumers with contaminated raw milk and milk products (Radostits et al., 2000).

*Corresponding e-mail address: prithul02@yahoo.co.uk 


\section{M.A.S. Sarker and others}

Polymerase chain reaction (PCR) assays can be applied to detect Brucella DNA from pure cultures and in clinical specimens, i.e. serum, whole blood and urine samples, various tissues, cerebrospinal, synovial or pleural fluid, and pus (Colmenero et al., 2010; Debeaumont et al., 2005; Queipo-Ortuño et al., 2006; 2008). The PCR is more sensitive than blood culture and more specific than serological tests (Al Dahouk et al., 2013). Culture for brucellosis diagnosis requires BSL 3 facilities and skilled personnel. In Bangladesh, no laboratory exists with BSL3 facilities for isolation of brucellae. Therefore, it is more feasible to detect Brucella DNA from clinical samples in Bangladesh. The analytical sensitivity can be further increased by using real-time PCR assays, which can detect as few as five bacteria per reaction (Navarro et al., 2006; Al Dahouk et al., 2007). Moreover, real-time PCR enables high-throughput screening of clinical samples and delivers results within a few hours. The aim of this study was to determine the seroprevalence of brucellosis in animals and humans and to detect Brucella DNA at the species level using real-time PCR.

\section{MATERIALS AND METHODS}

Venous blood samples were randomly and aseptically collected from cattle, buffaloes, sheep, goats and humans. A total of 1,452 blood samples was collected i.e. 913 from cattle, 99 from buffaloes, 40 from sheep, 50 from goats and 350 from human of Mymensingh Medical College Hospital, Central Cattle Breeding and Dairy Farm, Savar Dhaka; Mymensingh, Jamalpur, Gaibandha, Rangpur and Bagherhat districts of Bangladesh (Table 1). Clinical, epidemiological, managemental and reproductive information was recorded using questionnaires. Data on age, sex, geographical area, status of pregnancy, disease history, hygroma, reproductive disorder such as abnormal abdominal uterine discharge, abortion, retention of placenta, and reproductive diseases were recorded. The RBT was used as a screening test to identify infected animals and humans. iELISA (Svanova Biotech AB, Uppsala Sweden), RBT, SAT, CFT were performed according to the procedures described by OIE (2009) and the manufacturers. RBT positive sera were re-tested with SAT, CFT, ELISA and qRT-PCR.

\section{DNA extraction and real time PCR}

DNA was isolated from $200 \mu \mathrm{L}$ of RBT positive sera using the High Pure PCR Template Preparation Kit (Roche Diagnostics, Mannheim, Germany) according to the manufacturer's instructions. The resulting DNA concentration was determined photometrically using a Nano Drop ND-1000 UV-Vis spectrophotometer (NanoDrop Technologies, Wilmington, DE, USA). Samples tested RBT positive were investigated with Brucella IS711 genus specific RT PCR. Reactions were conducted in plastic capillaries using the light cycler 2.0 instrument (Roche, Mannheim, Germany) according to the method of Tomaso et al. (2010). Briefly, each reaction contained the primer pair IS711_S-5' -TTGTCGATGCTATCGGCCTAC-3'/IS711_R-5'-GGCAATGAAGGCC CTTAAGT-3' at a concentration of 500nM and the probes IS711_FL 5'-GAAGCTTGCGGACAGTCACCATA AT-Fluo-3'/IS711_LC-5'-Red640-GCCGGGTGTTGGCTTTATTCG-Pho-3' at a concentration of 200nM. The final $20 \mu \mathrm{L}$ reaction mixture included $4 \mu \mathrm{L}$ LC FastStart DNA Master Plus Master mix (Roche) supplemented with $1 \mu \mathrm{L}$ primers and $0.4 \mu \mathrm{L}$ probes and $2 \mu \mathrm{L}$ sample. Cycling parameters were as follows: a ten minute activation step at $95^{\circ} \mathrm{C}$ followed by 45 cycles of $95^{\circ} \mathrm{C}$ for $10 \mathrm{sec}, 55^{\circ} \mathrm{C}$ for $10 \mathrm{sec}$, and $72^{\circ} \mathrm{C}$ for $10 \mathrm{sec}$ (annealing and extension). Melting curve parameters were: $0 \mathrm{sec}$ at $95^{\circ} \mathrm{C}, 30 \mathrm{sec}$ at $45^{\circ} \mathrm{C}$ and $0 \mathrm{sec}$ at $95^{\circ} \mathrm{C}$ followed by a 30 sec cooling step at $40^{\circ} \mathrm{C}$. Data acquisition and evaluation was calculated by the instrument's software. Ct values below 40 were interpreted as positive. Subsequently the samples were examined with the Brucella IS711 species specific RT PCRs for B. abortus and B. melitensis according to the method of Probert et al. (2004). Briefly, for the detection of $B$. abortus each reaction contained the primers BabortF 5'-GCGGCTTTTCTATCACGGTA TTC-3', BabortR 5'-CATGCGCTATGATCTGGTTACG-3' at a final concentration of $300 \mathrm{nM}$ each and the genus specific probe 5'-6FAM-CGCTCATGCTCGCCAGACTTCAATG-BHQ1-3' at 100nM. The final $25 \mu \mathrm{L}$ reaction mixture included $12.5 \mu \mathrm{L}$ of TaqMan Universal Master Mix (Applied Biosystems) supplemented with $0.75 \mu \mathrm{M}$ primers, and $0.25 \mu \mathrm{M}$ probes and $2 \mu \mathrm{L}$ of sample DNA. Cycling parameters were as follows: an initial incubation at $50^{\circ} \mathrm{C}$ for $2 \mathrm{~min}$, followed by an initial denaturation step at $95^{\circ} \mathrm{C}$ for $10 \mathrm{~min}, 50$ cycles of $95^{\circ} \mathrm{C}$ for 
$25 \mathrm{~s}$ and $57^{\circ} \mathrm{C}$ for $60 \mathrm{~s}$ (annealing and extension). The identical conditions also applied to the reactions for detecting B. melitensis using the primer pair BmelitF 5'-AACAAGCGGCACCCCTAAAA-3', BmelitR 5'CATGCGCTATGATCTGGTTACG-3' and the genus specific probe 5'-6FAM-CAGGAGTGTTTCGGCTCA GAATAATCCACABHQ1-3'. The cycle threshold value $(\mathrm{Ct})$ was calculated by the instrument's software MxPro3000P v 4.01. Ct values below 40 were interpreted as positive.

\section{Statistical analysis}

The questionnaire based data was processed by Microsoft Excel and MSTATC, the results were statistically analyzed for interpretation by using Chi-square tests $\left(\chi^{2}\right)$. Significance was determined at 1 to $5 \%$ level where applicable.

\section{RESULTS AND DISCUSSION}

Out of 913 cattle and 99 buffalo sera, 48 cattle and 7 buffalo sera showed positive reaction in RBT resulting in a prevalence of $5.3 \%$ (95\% Confidence Interval (CI): $3.87-7.38)$ in cattle and $7.1 \%$ (95\% CI: $2.89-14.03)$ in buffaloes (Table 2).

Table 1. Prevalence of brucellosis in cattle and buffaloes, sheep \& goats, and humans.

\begin{tabular}{lcccccccc}
\hline Serum & Tested & $\begin{array}{c}\text { RBT } \\
\mathrm{n}(\%)\end{array}$ & $\begin{array}{c}\text { SAT } \\
\mathrm{n}(\%)\end{array}$ & $\begin{array}{c}\text { CFT } \\
\mathrm{n}(\%)\end{array}$ & $\begin{array}{c}\text { iELISA } \\
\mathrm{n}(\%)\end{array}$ & $\begin{array}{c}\text { BCSP } \\
\mathrm{n}(\%)\end{array}$ & $\begin{array}{c}\text { IS711 } \\
\mathrm{n}(\%)\end{array}$ & $\begin{array}{c}\text { B. abortus } \\
\mathrm{n}(\%)\end{array}$ \\
\hline Cattle & 913 & $48(5.3)$ & $5(0.5)$ & $26(2.8)$ & $1(0.1)$ & $17(1.9)$ & $2(0.2)$ & $8(0.9)$ \\
Buffaloes & 99 & $7(7.1)$ & $4(4.0)$ & $5(5.1)$ & $4(4.0)$ & $6(6.1)$ & $4(4.0)$ & $4(4.0)$ \\
Sheep \& goats & 90 & - & - & - & - & - & - & - \\
Humans & 350 & - & - & - & - & - & - & - \\
\hline
\end{tabular}

Out of 48 RBT positive sera of cattle 7 were $B$. abortus positive whereas out of 7 RBT positive buffalo sera 4 were $B$. abortus positive. The difference in detection level of $B$. abortus from cattle and buffalo sera was statistically significant $(\mathrm{p}=0.02)$. The odds of getting B. abortus DNA from RBT positive buffalo sera was 7.61 times higher than the same from cattle sera (Table 2).

Table 2. Serological test results

\begin{tabular}{l|c|c|c|c}
\hline RBT & SAT & CFT & iELISA & Number \\
\hline $1+$ & + & - & - & 2 \\
\hline $1+$ & + & + & - & 3 \\
\hline $2+$ & + & + & + & 4 \\
\hline $3+$ & + & - & + & 6 \\
\hline $3+$ & + & + & - & 7 \\
\hline $1+$ & - & + & - & 24 \\
\hline $2+$ & + & + & + & 6 \\
\hline $2+$ & - & + & - & 3 \\
\hline Sub Total & & & & 55 \\
\hline Suspicious & - & & - & 957 \\
\hline Total & & & & 1,012 \\
\hline
\end{tabular}




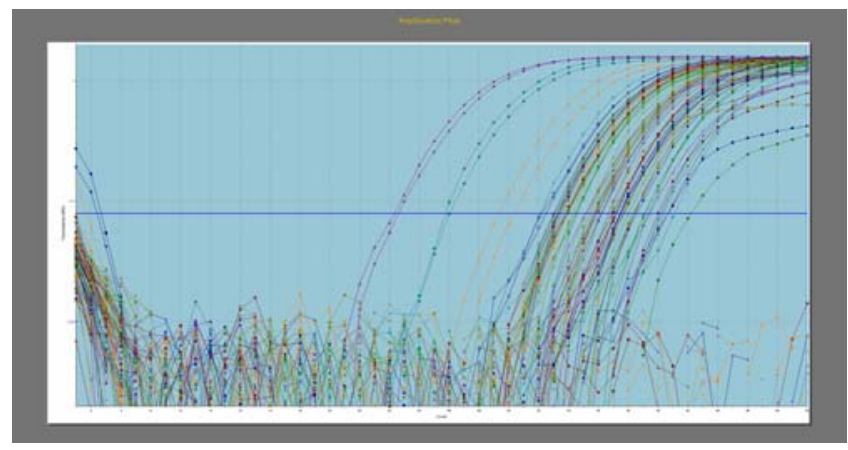

Figure 1. Amplification plot of B. abortus specific real-time PCR with DNA extracted from sera of cattle and buffaloes in Bangladesh

Figure 1 shows the amplification plot of B. abortus specific real time PCRs of seropositive cattle and buffalo sera. Out of 55 sera tested, 6 samples were seropositive in three additional tests used and infection can be considered as acute and active. Among 1,012 sera samples, 55 were positive only in RBT and 957 samples were suspicious negative in RBT (Table 2).

The relationship of serological tests and PCR is shown in Table $3 \& 4$. Seven cattle samples contained 1 Brucella abortus DNA, 48 sera were positive only in RBT (but negative in other two tests). On the other hand, 4 buffalo sera contained Brucella abortus DNA and 7 sera were positive in RBT (but negative in other two tests). The genus specific screening by PCR detected Brucella DNA in 4 sera, the species specific IS711 PCR also detected B. abortus DNA from the same 4 sera samples.

Table 3. Relationship of serological tests and PCR, Cattle sera $(n=913)$

\begin{tabular}{|c|c|c|c|c|c|c|c|c|c|c|c|c|c|c|}
\hline \multirow{2}{*}{ Area } & \multirow{2}{*}{$\begin{array}{l}\text { RBT } \\
\text { positive }\end{array}$} & \multirow{2}{*}{$\begin{array}{c}\text { RBT } \\
\text { intensity }\end{array}$} & \multicolumn{2}{|c|}{ SAT } & \multicolumn{2}{|c|}{ CFT } & \multicolumn{2}{|c|}{ iELISA } & \multicolumn{2}{|c|}{ BCSP } & \multicolumn{2}{|c|}{ IS711 } & \multicolumn{2}{|c|}{ B. abortus } \\
\hline & & & + & - & + & - & + & - & + & - & + & - & + & - \\
\hline Mymensingh & 5 & $1+$ & 1 & 4 & 4 & 1 & 0 & 5 & 4 & 1 & 0 & 5 & 0 & 5 \\
\hline Mymensingh & 2 & $2+$ & 0 & 2 & 0 & 2 & 0 & 2 & 2 & 0 & 0 & 2 & 0 & 2 \\
\hline Savar & 11 & $1+$ & 0 & 11 & 0 & 11 & 0 & 11 & 0 & 11 & 0 & 11 & 0 & 11 \\
\hline Kurigram & 27 & $1+$ & 2 & 25 & 18 & 9 & 0 & 27 & 17 & 10 & 0 & 27 & 6 & 21 \\
\hline Kurigram & 2 & $2+$ & 1 & 1 & 2 & 0 & 1 & 1 & 1 & 1 & 1 & 1 & 0 & 2 \\
\hline Kurigram & 1 & $3+$ & 1 & 0 & 1 & 0 & 0 & 1 & 1 & 0 & 1 & 0 & 1 & 0 \\
\hline
\end{tabular}

Table 4. Relationship of serological tests and PCR, buffalo sera ( $\mathrm{n}=99)$

\begin{tabular}{|c|c|c|c|c|c|c|c|c|c|c|c|c|c|c|}
\hline \multirow{2}{*}{ Area } & \multirow{2}{*}{$\begin{array}{l}\text { RBT } \\
\text { positive }\end{array}$} & \multirow{2}{*}{$\begin{array}{c}\text { RBT } \\
\text { intensity }\end{array}$} & \multicolumn{2}{|c|}{ SAT } & \multicolumn{2}{|c|}{ CFT } & \multicolumn{2}{|c|}{ iELISA } & \multicolumn{2}{|c|}{ BCSP } & \multicolumn{2}{|c|}{ IS711 } & \multicolumn{2}{|c|}{ B. abortus } \\
\hline & & & + & - & + & - & + & - & + & - & + & - & + & - \\
\hline Mymensingh & 1 & $1+$ & 1 & 0 & 1 & 0 & 0 & 1 & 1 & 0 & 0 & 1 & 0 & 1 \\
\hline Mymensingh & 1 & $2+$ & 1 & 0 & 1 & 0 & 1 & 0 & 1 & 0 & 1 & 0 & 1 & 0 \\
\hline Bagerhat & 2 & $1+$ & 0 & 2 & 1 & 1 & 0 & 2 & 1 & 1 & 0 & 2 & 0 & 2 \\
\hline Bagerhat & 2 & $2+$ & 2 & 0 & 2 & 0 & 2 & 0 & 2 & 0 & 2 & 0 & 2 & 0 \\
\hline Bagerhat & 1 & $3+$ & 1 & 0 & 0 & 1 & 1 & 0 & 1 & 0 & 1 & 0 & 1 & 0 \\
\hline
\end{tabular}

Out of 48 RBT positive sera of cattle, 7 (14.6\%) were B. abortus DNA positive whereas out of 7 RBT positive buffalo sera, $4(57.1 \%)$ contained B. abortus DNA. The difference in detection level of B. abortus from cattle and buffalo sera was statistically significant $(\mathrm{p}=0.02)$. The odds of getting $B$. abortus DNA from RBT positive buffalo sera was 7.61 times higher than from cattle sera (Table 2). 
As shown above seroprevalence of brucellosis in individual cattle and buffalo by RBT is $5.3 \%$ and $7.1 \%$, respectively (Table1) which is in line with published data showing a range between 2.4 to $18.4 \%$ at individual animal level and $62.5 \%$ at herd level. Serological prevalence in buffaloes was reported to be $2.87 \%$ (Amin et al., 2005; Rahman et al., 1997). In this study $10.9 \%(6 / 55)$ RBT positive bovines were found acutely infected by brucellosis. These acutely infected animals were positive in all tests. IgM and IgG are produced in early and later stage of the infection/disease, respectively. For this reason if a sample is positive in SAT and ELISA, it is considered as an acute infection. On the other hand, if a sample is positive only in the IgG ELISA, The infection is considered to be chronic. When a sample is positive only in agglutination tests like SAT, brucellosis has to be confirmed by an IgG detecting test like IgG ELISA (Godfroid et al., 2010; Seleem et al., 2010). However, this requires repeated sampling from the same animal which was not possible and not purpose of this study also. From the 7 cattle sera from which B. abortus DNA was detected, 2 were negative in SAT and 6 were negative in iELISA but all samples were positive in RBT. The infection in these animals might have been in the early stage which was detected by RBT only. In humans, Brucella DNA can be detected a long time after clinical cure reported by Navarro et al. (2006). This also indicates that the presence of only Brucella DNA does not mean acute infections. This may be similar in animals as seen in this study. The key shortcoming of PCR based techniques is that biovars can not be identified. Culture from milk and sera will be part of future investigations. It can be concluded that a combination of real time PCR with RBT, SAT and iELISA should be applied for detection brucellosis in cattle and buffaloes from Bangladesh in a future eradication program. The knowledge on prevalent Brucella species in humans and animals will help to initiate appropriate control measures against brucellosis.

\section{ACKNOWLEDGEMENTS}

The authors are grateful to National Reference Laboratory for brucellosis, Friedrich-Loeffler-Institute, Jena, Germany for laboratory and financial support.

\section{REFERENCES}

1. Al Dahouk S, Flèche PL, Nöckler K, Jacques I, Grayon M, Scholz HC, Tomaso H, Vergnaud G and Neubauer H (2007). Evaluation of Brucella MLVA typing for human brucellosis. Journal of Microbiological Methods 69: 137145.

2. Al Dahouk S, Sprague L and Neubauer H (2013). New developments in the diagnostic procedures for zoonotic brucellosis in humans. Revue Scientifiqueet Technique (International Office of Epizootics) 32: 177-188.

3. Amin K MR, Rahman MB, Rahman MS, Han JC, Park JH and Chae JS (2005). Prevalence of Brucella antibodies in sera of cows in Bangladesh. Journal of Veterinary Science 6: 223-226.

4. Colmenero JD, Morata P, Ruiz-Mesa JD, Bautista D, Bermúdez P, Bravo MJ and Queipo-Ortuño MI (2010). Multiplex real-time polymerase chain reaction: a practical approach for rapid diagnosis of tuberculous and brucellar vertebral osteomyelitis. Spine 35: E1392- E1396.

5. Debeaumont C, Falconnet P and Maurin M (2005). Real-time PCR for detection of Brucella spp. DNA in human serum samples. European Journal of Clinical Microbiology and Infectious Diseases 24: 842-845.

6. Food and Agriculture Organization (FAO) (2006). Bovine brucellosis. Animal health/disease cards.

7. Godfroid J, Nielsen K and Saegerman C (2010). Diagnosis of brucellosis in livestock and wild life. Croatian Medical Journal 51: 296-305.

8. Navarro E, Segura JC, Castno MJ and Solera J (2006). Use of real-time quantitative polymerase chain reaction to monitor the evolution of Brucella melitensis DNA load during therapy and post-therapy follow-up in patients with brucellosis. Clinical Infectious Diseases 42: 1266-1273.

9. OIE (2009). Bovine Brucellosis. Manual of standard for diagnostic test. List B disease OIE Terrestrial Manual,Chapter 2-4.

10. Olsen SC and Hennager SG (2010). Immune responses and protection against experimental Brucella suisbiovar 1 challenge in non vaccinated or B. abortus strain RB51-vaccinated cattle. Clinical and Vaccine Immunology 17: 1891-1895.

11. Queipo-Ortuño MI, Colmenero J, Bravo M, García-Ordoñez MÁ and Mora-Ta P (2008). Usefulness of a quantitative real-time PCR assay using serum samples to discriminate between inactive, serologically positive and active human brucellosis. Clinical Microbiology and Infection 14: 1128- 1134. 


\section{A. S. Sarker and others}

12. Queipo-Ortuño MI, Colmenero JD, Muñoz N, Baeza G, Clavijo E and Mora-Ta P (2006). Rapid diagnosis of Brucella epididymo-orchitis by real-time polymerase chain reaction assay in urine samples. Journal of Urology 176: 2290-2293.

13. Probert WS, Schrader KN, Khuong NY, Bystrom SL and Graves MH (2004). Real-time multiplex PCR assay for detection of Brucella spp., B. abortus and B. melitensis. Journal of Clinical Microbiology 42: 1290-1293.

14. Radostits OM, Gay CC, Blood DC and Hinchcliff KW (2000). Veterinary Medicine. 9th Ed, W.B. Saunders Company Ltd, London, pp: 871-882.

15. Rahman MA, Islam MS, Alam MGS and Shamsuddin M (1997). Sero-prevalence of brucellosis in the buffalo (Bubalus bubalis) of a selected area in Bangladesh. Buffalo Journal 2: 209-214.

16. Samaha H, Al-Rowaily M, Khoudair RM and Ashour HM (2008). Multicenter study of brucellosis in Egypt. Emerging Infectious Diseases14: 1916-1918.

17. Seleem MN, Boyle SM and Striranganathan N (2010). Brucellosis: a re-emerging zoonosis. Veterinary Microbiology 140: 392-398.

18. Tomaso H, Kattar M, Eickhoff M, Werney U, Dahouk SA, Straube E, Neubauer H and Scholz HC (2010). Comparison of commercial DNA preparation kits for the detection of Brucella in tissue using quantitative real-time PCR. BMC Infectious Diseases 10: 100. 